\title{
Neglected Hosts of Small Ruminant Morbillivirus
}

\section{Claudia Schulz, ${ }^{1}$ Christine Fast, Kore Schlottau, Bernd Hoffmann, Martin Beer}

Eradication of small ruminant morbillivirus (PPRV) is targeted for 2030. PPRV lineage IV is found in much of Asia and Africa. We used PPRV lineage IV strain Kurdistan/2011 in transmission trials to investigate the role of pigs, wild boar, and small ruminants as PPRV reservoirs. Suids were a possible source of infection.

$\mathrm{P}$ este des petits ruminants is one of the most serious (economically and clinically) transboundary animal diseases (1-3). Of 4 lineages, small ruminant morbillivirus (previously called peste des petits ruminants virus; PPRV) lineage IV (PPRV-LIV) has spread the most widely in the past decade, particularly in Asia, and increasingly dominates the PPRV lineages in Africa $(2,4)$. Morbidity and mortality rates for goats are high, up to $100 \%$; however, sheep can be subclinically infected and play a major role in the silent spread of PPRV over large distances and across borders (3). The role of other wild and domestic Artiodactyls in the epidemiology of PPRV is unknown or insufficiently understood (3). Pigs are considered dead-end hosts for PPRV (5). In an experimental infection study, pigs infected with PPRV lineage II (LII) strains did not transmit PPRV to goats, but they can transmit the closely related Rinderpest morbillivirus to cattle (6). To determine the pathogenesis of PPRV-LIV infection in pigs and wild boar and the capability of these suids to transmit PPRV in comparison with that of goats and sheep, we conducted 4 independent transmission trials during 2015-2016. The experimental protocol was reviewed by a state ethics commission and approved by the State Office for Agriculture, Food Safety and Fisheries of Mecklenburg-Vorpommern, Rostock, Germany (LALLF M-V/TSD/7221.3-1-018/14).

\section{The Study}

In 4 trials (trials 1-4; Table), we intranasally inoculated suids with a recent PPRV-LIV strain (Kurdistan/2011 $[7,8])$. Contact control animals were added 2 days later. We recorded clinical signs and temperature regularly and collected samples to evaluate the suitability of different virologic, serologic, and pathological methods for detecting PPRV infection. We conducted statistical analyses to

Author affiliation: Friedrich-Loeffler-Institut, Greifswald-Insel

Riems, Germany

DOI: https://doi.org/10.3201/eid2412.180507 calculate whether PPRV RNA loads in secretions and excretions (oral, nasal, and fecal swab samples) collected over time from pigs, wild boar, goats, and sheep differed significantly and to determine correlations between the results of virus isolation and PCR assays by using swab samples and purified leukocytes as sample materials (online Technical Appendix, https://wwwnc.cdc.gov/EID/ article/24/12/18-0507- Techapp1.pdf).

As expected, goats showed the typical moderate to severe clinical signs (trials 1 and 3) reported previously (7-9). Clinical signs in PPRV-infected sheep (trial 4) were generally mild to moderate, as previously described $(3,8)$. Contact controls showed similar clinical signs. One PPRVinfected sheep showed severe clinical signs similar to those of the goats. Surprisingly, all PPRV infected pigs and wild boar (trials 1-3) showed various mild to moderate clinical signs, including fever and reduced general condition (all suids), diarrhea (pig 1, boar 1-4), and ocular (pigs 1-3) and nasal (boar 4) discharge typical for PPRV infection (Figure 1; Figure 2, panels A-C; online Technical Appendix). PPRV-induced immunosuppression may predispose affected animals to secondary infections $(3,9)$ as reflected by distinct severe leukocytopenia in pigs and goats a few days after inoculation. Different expressions of clinical signs after PPRV infection might have been caused by concurrent infections with other pathogens or differences in individual resistance to PPRV infection (9). In the 4 wild boar, for example, Balantidium coli, detected by histopathologic examination (data not shown), might have been an additional factor causing the diarrhea (10). Nevertheless, similar to the lack of clinical signs reported for pigs infected with a PPRV-LII strain (6), the 2 pigs in trial 3 showed only mild clinical signs.

Contact transmission of PPRV from intranasally infected pigs to 1 contact goat and 1 pig was noted (trial 1). This pig was refractory to intranasal infection but was infected by contact at a similar time as one of the goats. Furthermore, PPRV was transmitted from intranasally infected goats to contact pigs (trial 3) (Table). Hence, in contrast to the findings of Nawathe and Taylor (6), who reported contact transmission of a PPRV-LII strain from experimentally infected goats to contact pigs but not vice versa, our transmission trials demonstrated that a complete interspecies transmission cycle of a PPRV-LIV strain between goats and pigs, and possibly also intraspecies transmission between pigs, can be maintained. The virulence of ${ }^{1}$ Current affiliation: University of Veterinary Medicine Hannover, Hannover, Germany. 
Table. Design and outcomes of PPRV transmission trials, Germany*

\begin{tabular}{|c|c|c|c|c|c|c|c|}
\hline \multirow[b]{2}{*}{$\begin{array}{l}\text { Trial } \\
\text { no.† }\end{array}$} & \multirow[b]{2}{*}{ Trial } & \multirow[b]{2}{*}{$\begin{array}{c}\text { No. } \\
\text { inoculated } \\
\text { animals }\end{array}$} & \multirow[b]{2}{*}{$\begin{array}{l}\text { No. contact } \\
\text { controls }\end{array}$} & \multicolumn{4}{|c|}{ Outcomes } \\
\hline & & & & $\begin{array}{l}\text { Seroconversion, } \\
\text { total no. by } \\
\text { species }\end{array}$ & $\begin{array}{l}\text { Excretion of } \\
\text { PPRV RNA, total } \\
\text { no. by species }\end{array}$ & $\begin{array}{c}\text { Excretion of } \\
\text { infectious PPRV, } \\
\text { total no. by species }\end{array}$ & $\begin{array}{l}\text { Contact transmission (no. } \\
\text { contact-infected/total no. } \\
\text { in contact) }\end{array}$ \\
\hline 1 & P-GP & & & & $3 P, \ddagger 2 G$ & $1 P, 2 G$ & /1/P $\ddagger)$ \\
\hline 2 & v & & & & & & $\pi<5$ \\
\hline 3 & & & & & $2 \mathrm{G}, 2 \mathrm{P}$ & $2 G$ & \\
\hline $4 \pi$ & S-S & $5 S$ & $5 S$ & & $5 S$ & $5 S$ & No $(0 / 5 S)$ \\
\hline \multicolumn{8}{|c|}{ 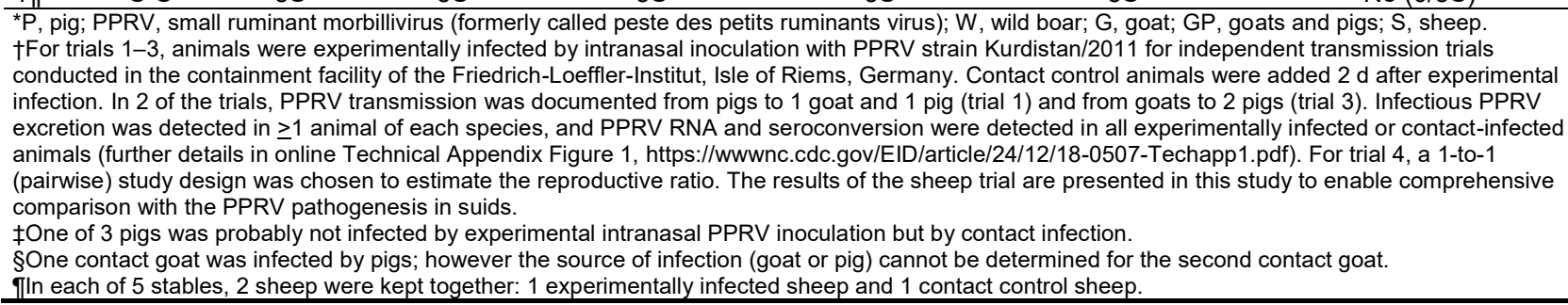 } \\
\hline
\end{tabular}

the PPRV lineage or strain is possibly a factor influencing the susceptibility to PPRV infection and the probability of PPRV transmission $(9,11)$.

From 2 of 4 wild boar (trial 2), PPRV was isolated from a few fecal swab samples but was not transmitted to the contact goats or pigs. Unexpectedly, none of the intranasally infected sheep transmitted PPRV to any of the contact sheep. The considerable differences in transmission efficiency between goats and the other Artiodactyls can be explained by higher PPRV loads excreted by goats
(Figure 1). Statistically significantly higher PPRV RNA loads over time were found in PPRV-infected goats than in suids and sheep. Peak viral loads in goat samples were up to $1 \log$ step (PCR) and $2.5 \log$ steps (virus isolation) higher $\left(9.3 \times 10^{7}\right.$ copies $/ \mathrm{mL} ; 10^{6.0} \mathrm{TCID}_{50}[50 \%$ tissue culture infective dose $] / \mathrm{mL}$ ) than in pig and wild boar samples $\left(1.5 \times 10^{7}\right.$ copies $/ \mathrm{mL} ; 10^{3.5}$ TCID $\left._{50} / \mathrm{mL}\right)$. Of note, peak viral loads in sheep $\left(10^{4} \mathrm{TCID}_{50} / \mathrm{mL}\right)$ were only slightly higher than those in pigs and wild boar, which may explain why none of the sheep transmitted PPRV to the contact
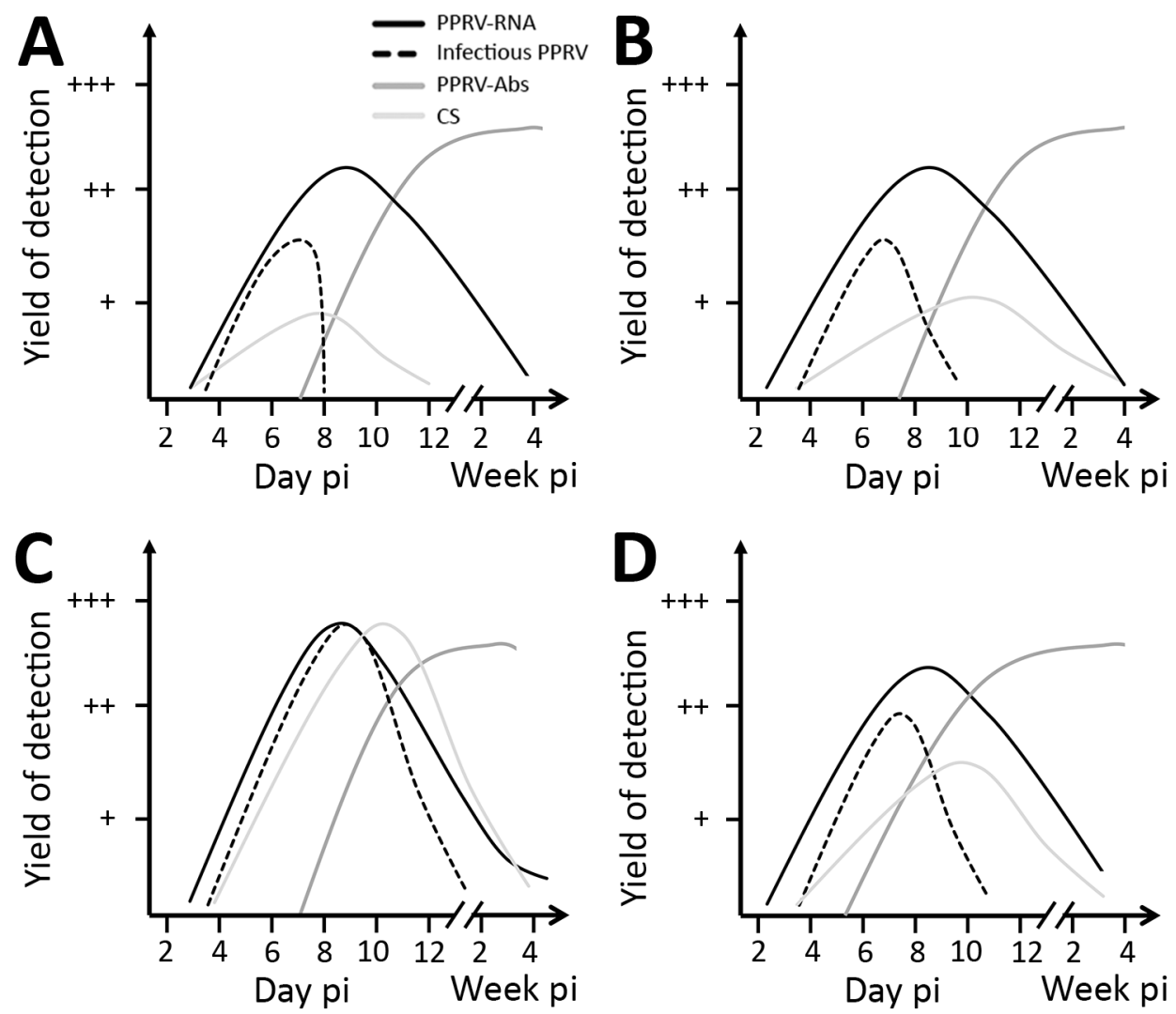

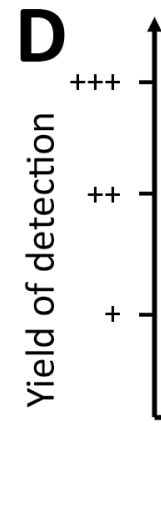

Figure 1. Progression of virologic, serologic, and clinical parameters analyzed in pigs $(A)$, wild boar (B), goats $(C)$, and sheep (D) in Germany after experimental infection with PPRV lineage IV strain Kurdistan/2011. Results are shown for reverse transcription quantitative PCR (solid black lines), endpoint dilution assay (dashed black lines), competitive ELISA (dark gray lines), and clinical score sheets (light gray lines). A detailed description of the infection experiment is provided in the online Technical Appendix (https://wwwnc.cdc.gov/EID/ article/24/12/18-0507-Techapp1. pdf). Abs, antibodies; CS, clinical signs; pi, postinfection; PPRV, small ruminant morbillivirus (formerly called peste des petits ruminants virus). 
Figure 2. Clinical signs observed in wild boar and pigs and small ruminant morbillivirus (formerly called peste des petits ruminants virus; PPRV) antigen detection in a pig tonsil in experimental study of PPRV transmission, Germany.

A) Purulent nasal discharge in wild boar 4 at 8 days after infection; B) diarrhea in wild boar 4 at 7 days after infection; C) swollen eyelids in pig 3 at 10 days after infection; D) PPRV antigen (red) in the tonsil of pig 1 at 30 days after infection $(\approx 22$ days after contact infection of pig 1), by immunohistochemical staining with monocloncal mouse anti-PPRV; scale bar indicates $50 \mu \mathrm{m}$. Clinical signs in the 3 pigs in trial 1 included a transient rise in body temperature, ruffling bristles, diarrhea, reduced activity and food intake/ slight emaciation, swelling of the eyelids, mild to severe conjunctivitis, and mucous to purulent ocular discharge in the
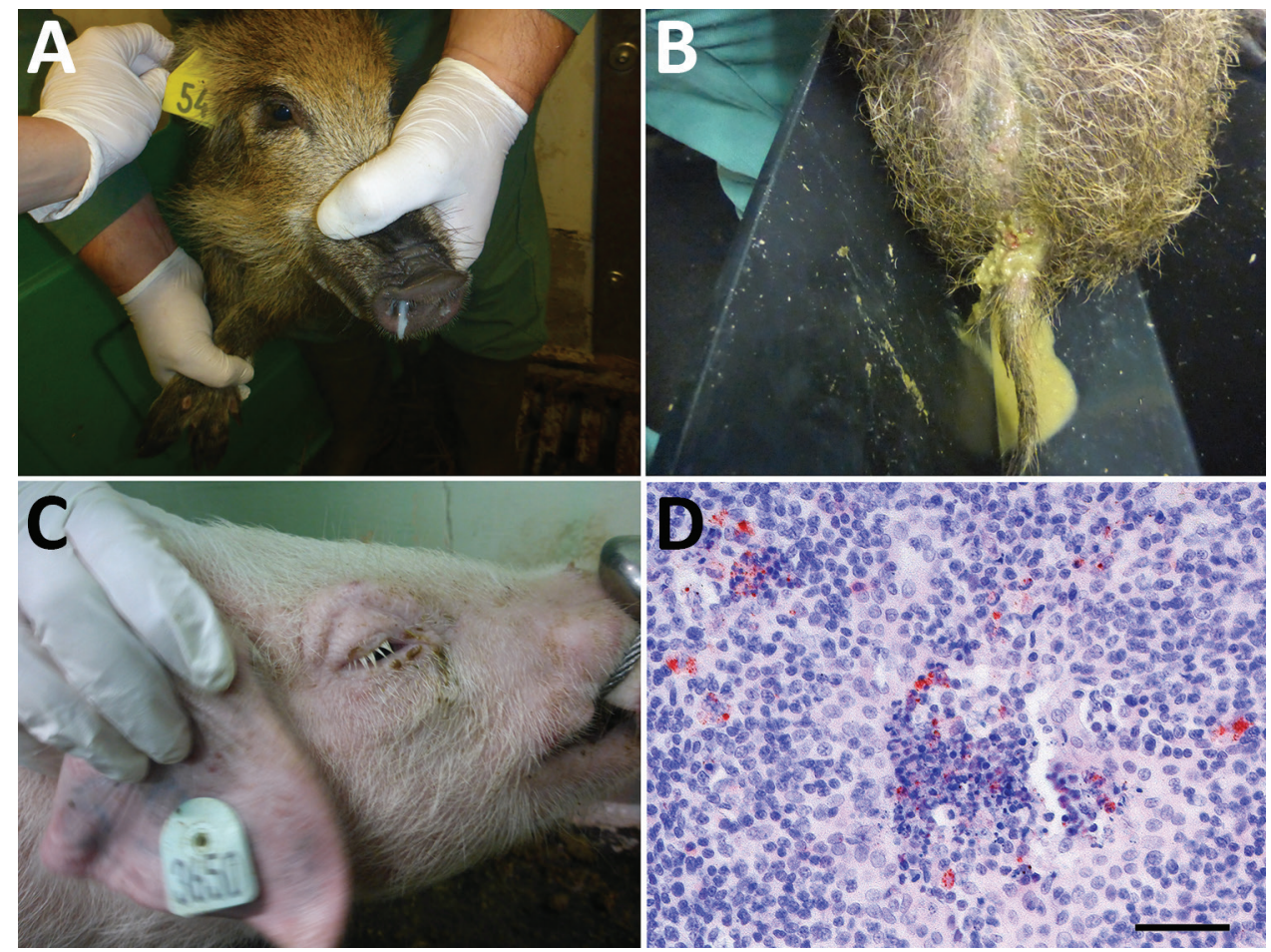

first days after infection. In the 4 wild boar in trial 2, clinical signs included transiently increased body temperature, diarrhea (including fresh blood), reduced general condition, inappetence, and mucopurulent nasal discharge. A detailed description of the infection experiments is provided in the online Technical Appendix (https://wwwnc.cdc.gov/EID/article/24/12/18-0507-Techapp1.pdf).

control sheep. The higher viral loads in goats could also explain the $\approx 4$ days earlier contact infection of the contact pigs in trial 3 than the contact goat and pig in trial 1. Besides a higher innate susceptibility to PPRV infection observed for goats compared with sheep and suids, the infective dose may play a role in the efficiency of transmission and infection dynamics of PPRV in suids as previously reported for goats (9) and camelids (12).

We detected seroconversion in all PPRV-infected animals by using competitive ELISA and neutralization tests. Neutralizing antibody titers were moderate to high in suids and goats $\left(2.16-2.96 \log _{10} \mathrm{ND}_{50}\right.$ [virus neutralization in 50\% of replicates]) and slightly lower in sheep (1.76-2.56 $\left.\log _{10} \mathrm{ND}_{50}\right)$. After seroconversion, no PPRV could be isolated from swab and purified leukocyte samples, but PPRV RNA was detected in swab samples for at least 3-4 weeks after infection in all species, with individual differences (Figure 1; online Technical Appendix). Correlation analyses revealed a poor to excellent correlation of PCR and virus isolation results before seroconversion, depending on the animal species. Possible reasons for (transient) PPRV RNA persistence are infection of neurons followed by transsynaptic spread (13). Indeed, PPRV RNA was detected in single or multiple brain samples of 2 sheep, 4 goats, and in the choroid plexus of 1 pig, 1 wild boar, and 3 goats. PPRV RNA in the choroid plexus might have been associated with PPRV-infected immune cells, as has been reported for ferrets infected with closely related canine morbillivirus (14). Immunohistochemistry demonstrated that PPRV antigens in other tissues were often associated with immune cells. For PPRV diagnosis in the examined species, tissue of the lymphoreticular system, in particular tonsils (Figure 2, panel D), head and lung-associated lymph nodes, mesenteric lymph nodes, and small intestinal Peyer's patches, were found most suitable for postmortem diagnosis with PCR and immunohistochemistry. PCR was the most sensitive virologic method independent from the sample material, and competitive ELISA proved reliable for serologic PPRV diagnosis (online Technical Appendix).

\section{Conclusions}

Transmission trials with a virulent PPRV-LIV strain revealed that suids are an unexpected possible source for PPRV infection. Therefore, domestic pigs and wild boar should be considered as possible PPRV reservoir hosts. This finding is especially relevant to stringent control programs. The epidemiologic role of suids in the spread of PPRV, as maintenance or spillover hosts (15), should be further investigated in field and experimental studies using different PPRV lineages and strains at different environmental and experimental conditions. 


\section{Acknowledgments}

We thank Holger Freese, Christian Korthase, Isabell Metz, Karin Pinger, Anja Schulz, and Susanne Zahnow for their excellent technical assistance; the staff of the experimental animal facilities for great assistance and dedicated animal care; Sandra Blome, Bernd Haas, and Jana Pietschmann for scientific and organizational advice; Reiner Ulrich and Jan Schinköthe for excellent support with gross pathology; and Jörn Gethmann, Mario Ziller, Carola Sauter-Louis, and Hans-Hermann Thulke for biostatistical advice.

We also thank the European Commission Animal Health, the Welfare European Research Area Network Fund, and the German Federal Office for Agriculture and Food (grant no. 2813ERA074) for providing support for epidemiologic research under the Improved Understanding of the Epidemiology of Peste-des-Petits Ruminants project.

\section{About the Author}

Dr. Schulz is a postdoctoral researcher at the University of Veterinary Medicine Hannover, Germany. Her primary research interests are the pathogenesis and epidemiology of emerging and vectorborne diseases in wild and domestic animals.

\section{References}

1. Banyard AC, Parida S, Batten C, Oura C, Kwiatek O, Libeau G. Global distribution of peste des petits ruminants virus and prospects for improved diagnosis and control. J Gen Virol. 2010;91:2885-97. http://dx.doi.org/10.1099/vir.0.025841-0

2. Munir M. Role of wild small ruminants in the epidemiology of peste des petits ruminants. Transbound Emerg Dis. 2014;61:411-24.

3. European Food Safety Authority. Scientific opinion on peste des petits ruminants: EFSA Panel on Animal Health and Welfare (AHAW). EFSA J. 2015;13:3985.

4. Baron MD, Parida S, Oura CA. Peste des petits ruminants: a suitable candidate for eradication? Vet Rec. 2011;169:16-21. http://dx.doi.org/10.1136/vr.d3947

5. World Organisation for Animal Health. Peste des petits ruminants [cited 2018 Oct 5]. http://www.oie.int/fileadmin/Home/eng/
Animal_Health_in_the_World/docs/pdf/Disease_cards/PESTE_ DES PETITS RUMINANTS.pdf

6. Nawathe DR, Taylor WP. Experimental infection of domestic pigs with the virus of peste des petits ruminants. Trop Anim Health Prod. 1979;11:120-2. http://dx.doi.org/10.1007/BF02237785

7. Hoffmann B, Wiesner H, Maltzan J, Mustefa R, Eschbaumer M, Arif FA, et al. Fatalities in wild goats in Kurdistan associated with peste des petits ruminants virus. Transbound Emerg Dis. 2012; 59:173-6. http://dx.doi.org/10.1111/j.1865-1682.2011.01270.x

8. Wernike K, Eschbaumer M, Breithaupt A, Maltzan J, Wiesner H, Beer M, et al. Experimental infection of sheep and goats with a recent isolate of peste des petits ruminants virus from Kurdistan. Vet Microbiol. 2014;172:140-5. http://dx.doi.org/10.1016/ j.vetmic.2014.05.010

9. Pope RA, Parida S, Bailey D, Brownlie J, Barrett T, Banyard AC. Early events following experimental infection with peste-des-petits ruminants virus suggest immune cell targeting. PLoS One. 2013;8:e55830. http://dx.doi.org/10.1371/ journal.pone. 0055830

10. Deplazes P, Eckert J, Zahner H. Lehrbuch der Parasitologie für die Tiermedizin. 3rd ed. Stuttgart (Germany): EnkeVerlag; 2012.

11. Couacy-Hymann E, Bodjo C, Danho T, Libeau G, Diallo A. Evaluation of the virulence of some strains of peste-des-petitsruminants virus (PPRV) in experimentally infected West African dwarf goats. Vet J. 2007;173:178-83. http://dx.doi.org/10.1016/ j.tvj1.2005.08.020

12. Wernery U. Peste des petits ruminants (PPR) in camelids with own investigations. J Camel Pract Res. 2011;18:219-23.

13. Lin WH, Kouyos RD, Adams RJ, Grenfell BT, Griffin DE. Prolonged persistence of measles virus RNA is characteristic of primary infection dynamics. Proc Natl Acad Sci U S A. 2012;109: 14989-94. http://dx.doi.org/10.1073/pnas.1211138109

14. Ludlow M, Rennick LJ, Nambulli S, de Swart RL, Duprex WP. Using the ferret model to study morbillivirus entry, spread, transmission and cross-species infection. Curr Opin Virol. 2014;4:15-23. http://dx.doi.org/10.1016/j.coviro.2013.11.001

15. Palmer MV, Thacker TC, Waters WR, Gortazar C, Corner LA. Mycobacterium bovis: a model pathogen at the interface of livestock, wildlife, and humans. Vet Med Int. 2012;2012. http://dx.doi.org/10.1155/2012/236205

Address for correspondence: Claudia Schulz, University of Veterinary Medicine Hannover, Bünteweg 17, 30539 Hannover, Germany; email: claudia.schulz@tiho-hannover.de 